${ }^{1}$ Institute and Research Center São Leopoldo Mandic, Campinas, Brazil.

${ }^{2}$ Department of Restorative

Dentistry, Piracicaba Dental School, University of Campinas (UNICAMP) Piracicaba, Brazil.
Corresponding author:

Vanessa Cavalli

University of Campinas, Piracicaba

Dental School

Av. Limeira, 901, 13414-018

Piracicaba, SP, Brazil

email:vcavalli@yahoo.com

Received: September 13, 2018

Accepted: September 11, 2019

\section{Do metal alloy primers increase the bond strength of orthodontic tubes?}

\author{
Keity Cristina Moreira de Oliveira ${ }^{1}$, Daylana Pacheco \\ da Silva², Cecília Pedroso Turssi ${ }^{1}$, Flávia Lucisano \\ Botelho do Amaral ${ }^{1}$, Vanessa Cavalli ${ }^{2, *}$
}

Aim: To evaluate the bond strength (BS) and failure mode of orthodontic tubes treated with different alloy primers at the interface among enamel, resin and orthodontic tubes. Methods: Orthodontic tubes were bonded to the enamel of 80 bovine incisors with the orthodontic resin (Transbond XT, 3M Unitek). Prior to bonding, the tubes were chemically treated with $(n=20)$ Metal/Zirconia Primer (MZ, Ivoclar), Scothbond Universal (SB, 3M Espe); Orthoprimer (OP, Morelli) or left untreated (Control - C). Specimens were submitted to 5,000 thermal cycles ( 5 and $55^{\circ} \mathrm{C}$ ) to age the bonded interface. A shear BS test and failure modes were conducted, and the results were analyzed using one-way analysis of variance and Fisher's exact test, respectively. Results: No differences were observed among groups regardless of the type of alloy primer used $(p=0.254)$. However, no differences were observed among the failure modes of the groups tested $(p=0.694)$. The adhesive failure mode between the resin and enamel was the most prevalent failure (45\%) for groups OP and $\mathrm{C}$, whereas cohesive failure in the orthodontic resin was the most prevalent failure (40\%) for groups SB and MZ. Conclusion: Alloy primers were unable to increase the BS of the orthodontic tubes to enamel.

Keywords: Shear strength. Dental bonding. Materials testing. Alloys. Orthodontics. 


\section{Introduction}

The use of tubes as an option for orthodontic treatment was responsible for a major advancement in orthodontics, and it was possible due to improvements in adhesive systems and orthodontic composite resins, which provide reliable and long-term enamel adhesion ${ }^{1}$. The orthodontic tubes offer advantages over traditional systems, such as orthodontic bands, as they facilitate hygiene, eliminate the need for spacers, and decrease the possibility of periodontal disease and secondary carious lesions ${ }^{2}$.

To be effective, tubes must be able to withstand the forces that orthodontic mechanics generate, as well as masticatory forces. In addition, they should present a shear bond strength (BS) greater than $8 \mathrm{MPa}$, which is the minimum value necessary to maintain enamel adhesion under such circumstances ${ }^{3}$. However, under clinical conditions, enamel adhesive failures leading to the debonding of orthodontic tubes can occur $^{4-6}$. In fact, debonding is the reason for many failures, causing $66 \%$ of total failures in molars ${ }^{7}$. Adhesive failures are frequently associated with complications with the bonding technique, moisture contamination, occlusal contacts, the presence of aprismatic enamel, and changes in the enamel-etching pattern ${ }^{8}$. Although the tubes can be replaced or submitted to a new bonding procedure, these procedures involve additional chairside appointments, which compromises the treatment progress.

The interface between the orthodontic tube and enamel is not the only site susceptible to failure. Debonding can also occur between the tube and the orthodontic resin, and although a number of treatments are described to improve adhesion to ename ${ }^{4-6}$, only a few are proposed to increase bonding on the metal surface. Mechanical treatments designed to increase roughness, such as aluminum oxide blasting, the use of a diamond drill ${ }^{9}$, and chemical treatment with the use of silane ${ }^{10}$, are amid the reported alternative treatments for the metal surface.

Base metal alloys containing chrome in their composition ( $\mathrm{Ni}-\mathrm{Cr}$, Ni-Cr-Be, $\mathrm{Co}-\mathrm{Cr}$ ) can oxidize when in contact with atmospheric air, forming a passivation layer ${ }^{11}$. Some adhesive monomers that can chemically bond to the oxide film on the metal surface have been incorporated into resin cements with the goal of improving bonding across the interface. Therefore, bonding between adhesive monomers and alloys is the result of a micromechanical interocking promoted by surface roughness, and a chemical interaction between the oxide film of the metal surface and the carboxylic of phosphate acidic monomer of the resin cements ${ }^{12}$. With the aim of overcoming the absence of adhesive monomers in the composition of resin cements, metal alloy primers were developed to be applied on the surfaces of alloys prior to cementation $^{13}$. Previous, studies have demonstrated alloy primers' ability to improve bonding between polymer-based materials and metallic surfaces ${ }^{14,15}$.

The first monomer to be used for adhesion to metal was 4-META (methacryloyloxyethy trimellitate anhydride), which was designed to eliminate the need for mechanical retention and increase adhesion ${ }^{16}$. Later, monomers containing either phosphoric or carboxylic acid groups, such as 11-methacryloxyunden, decarboxylic acid (MAC10), 10 methacryloxydecyl dihydrogen phosphate (10 MDP), vinylbenzyl-n-propylamino-triazine-dithiol (VBATDT), and 6-methacryloxyhexyl-2-thiouracil-5-caboxylate (MTU-6), 
were synthesized ${ }^{14-16}$. The primers applied on the surface of the metal may contain MDP, VBTDT, MTU-6, MAC-10, or the combination of these monomers. The functional monomer of 10-MDP is able to react chemically with the chromium oxide of the casting surface to promote adhesion ${ }^{14,16}$. MDP has two functional groups: One is a di-valent phosphoryl group that chemically bonds to the metal atoms of the metal surface, and the other is a methacryloyl group that copolymerizes with resin monomers either in the adhesive or in the resin cement composition"14,16. Recently, "universal "or "multimold" adhesives containing both silane and a functional monomer have been developed and are indicated to bond to metal surfaces. However, these universal adhesives' ability to bond to metal alloys is still being debated ${ }^{16}$.

Since alloy primers are indicated for metal surfaces, the potential of increasing the BS of orthodontic tubes seems to be promising ${ }^{17}$. However, the literature is scarce in studies evaluating the use of primers in metal orthodontic devices. Therefore, the aim of this study was to evaluate the BS and failure mode at the interface among enamel, resin, and orthodontic tubes treated with various metal primers. The null hypothesis was that no differences would be found in the BS and failure mode among groups.

\section{MATERIALS AND METHODS}

\section{Experimental design}

The experimental units consisted of 80 bovine incisors, and orthodontic tubes were bonded to the enamel buccal surfaces. Before bonding, the orthodontic tubes received $(n=20)$ two alloy primers (Metal/Zirconia Primer - $M Z$ and Orthoprimer - OP) and one multi-mode adhesive (Scothbond Universal - SB). The control group was left untreated $(n=20)$. The response variables were shear BS (in MPa) and the failure mode of the deboned area. The commercial name, manufacturer, and composition of the alloy primers are shown in Table 1.

Table 1. Composition of the metal primers and orthodontic composite.

\begin{tabular}{lc}
\hline $\begin{array}{l}\text { Commercial name and } \\
\text { manufacutrer }\end{array}$ & Composition \\
\hline $\begin{array}{l}\text { Metal/Zirconia primer } \\
\text { (MZ, Ivoclar Vivadent, Schaan, } \\
\text { Liechtenstein) }\end{array}$ & Methacrylate of phosphonic acid and methacrylate cross-linked in organic \\
solvent.
\end{tabular}

Scotchbond Universal (SB, 3M/ESPE, St. Paul, MN, USA)
BIS-GMA, HEMA, silane treated silica, water, ethanol, decamethylenedimethacrylate,10-decanediol phosphate methacrylate, acrylic copolymer and itaconic acid, camphorquinone, N, N-dimethylbenzocaine, 2-dimethylamonoethyl methacrylate, methyl ethyl ketone.
Orthoprimer (OP, Morelli, Sorocaba, Brazil)
Bis-GMA, TEG-DMA, HEMA, DMPT, camphorquinone, hydroxytoluenebutylated, dimethyl aminoethyl methacrylate.

Primer: Bisphenol A diglycidyl ether dimethacrylate, TEG-DMA, triethylene glycol dimethacrylate, triphenylantimonium, 4- (dimethalamino) -benzethanol, d-1-camphorquinone, hydroquinone. Resin: Bis-GMA, bisphenol A bis

Transbond XT (3M-Unitek, Monrovia, USA)

(2-hydroxyethyl ether) dimethacrylate, quartz treated silane, silane treated silane, silanodimethacrylate, Diphenyliodonium hexafluorophosphate

BIS-GMA- bisphenolglicedyl methacrylate; TEG-DMA-triethylene glycol dimethacrylate; HEMA-hydroxyethyl methacrylate; DMPT-dimethyl-p-toluidine. 


\section{Specimen preparation}

Eighty bovine incisors crowns with enamel free of defects or cracks were selected and were stored in a $0.1 \%$ thymol solution for 24 hours. After debridement and pumicing, the teeth were embedded in polystyrene resin with the buccal surfaces facing up and sonicated.

Enamel bonding was performed according to the manufacturer's instructions for the orthodontic composite (Transbond XT). Teeth were cleaned with water spray (15 s), air dried (15 s), and acid etched with 37\% phosphoric acid gel for $30 \mathrm{~s}$. The surface was rinsed with air-water spray for $20 \mathrm{~s}$ and air dried for $10 \mathrm{~s}$. The primer of the Transbond XT system was applied on the enamel surface, then sprayed with a mild air spray for $5 \mathrm{~s}$ and light cured for $20 \mathrm{~s}$. The orthodontic composite (Transbond $\mathrm{XT}$ ) was applied on the inner surface of the tube and fixed on the enamel. Light curing was performed for $40 \mathrm{~s}$ (20 s in the mesial and $20 \mathrm{~s}$ in the distal sites) using a LED light-curing unit (Bluephase, Ivoclar, Liechtenstein, with irradiance of $\left.1200 \mathrm{~mW} / \mathrm{cm}^{2}\right)$.

Before the tube was bonded to the enamel surface, the base of the orthodontic tube was treated according to each experimental group:

- $\quad M Z$ : The primer was applied on the base of the tube (180 s) and air dried (5s).

- OP: The primer was applied on the base of the tube (180 s) and air dried (5s).

- SB: The universal adhesive was applied on the base of the tube (20 s) and air-dried (5s).

- Control: No treatment was performed on the tube.

\section{Thermal cycling}

The samples were stored for $24 \mathrm{~h}$ in distilled water at $37^{\circ} \mathrm{C}$, and for the purpose of aging the bonding interface, 5,000 thermal cycles were performed (MSCT-3, Marcelo Nucci ME, São Carlos, Brazil) at 5 and $55^{\circ} \mathrm{C}\left( \pm 1^{\circ} \mathrm{C}\right)$ with a dwell time of one minute each.

\section{Shear bond strength test}

Forty-eight hours later, specimens were submitted to a shear test in the occlusal-cervical direction, with the blade placed at the enamel and resin/tube interface. The tests were performed in a universal testing machine (EMIC- DL 2000, Instron Brasil Scientific Equipment LTDA, São José dos Pinhais, Brazil) with a load cell of $1 \mathrm{kN}$ at a crosshead speed of $0.5 \mathrm{~mm} / \mathrm{min}$. The maximum force $(\mathrm{N})$ up to failure was recorded. The shear $\mathrm{BS}$ (in $\mathrm{MPa}$ ) was calculated from the force and the bonded area of the tube to the enamel surface.

\section{Failure mode}

The failure mode of the debonded interface was observed under a stereomicroscope at $40 x$ magnification. Debonding was classified (Table 2 ) based on a previous report ${ }^{18}$. 
Table 2. Failure mode classification

\begin{tabular}{|c|c|}
\hline Standard & Type of Failure \\
\hline 1 & $\begin{array}{l}\text { Adhesive failure between orthodontic composite and the base of the orthodontic tube ( } 100 \% \text { of } \\
\text { the composite remains on enamel surface) }\end{array}$ \\
\hline 2 & $\begin{array}{c}\text { Cohesive failure in the orthodontic composite ( } 50 \% \text { of the composite remains at the base of the } \\
\text { orthodontic tube and } 50 \% \text { bonded on enamel) }\end{array}$ \\
\hline 3 & $\begin{array}{c}\text { Adhesive failure between orthodontic composite and enamel ( } 100 \% \text { of the composite remains } \\
\text { on the tube) }\end{array}$ \\
\hline 4 & Cohesive enamel fracture \\
\hline
\end{tabular}

\section{Statistical analysis}

Shear BS data were submitted to exploratory analysis to verify normality and homoscedasticity, and they were also submitted to parametric one-way analysis of variance (ANOVA). The fracture mode was analyzed using Fisher's exact test. In all analyses, SAS software (SAS Institute Inc., Cary, NC, USA, Release 9.2, 2010) was used considering the level of significance of $5 \%$.

\section{RESULTS}

No significant difference was found among groups in terms of shear BS values $(p=0.254)$ as observed in Table 3. Additionally, no significant difference $(p=0.694)$ was observed in the failure mode distribution of the adhesive interface as a function of the treatments. The most common failure mode was type 3 (adhesive failure between the orthodontic composite and enamel), in which no orthodontic composite remnant was found in the enamel ( $45 \%$ of the experimental units). The least prevalent failure was type 1 (only in the SB group), in which the base of the orthodontic tube did not exhibit a resin remnant and all of the resin remained on the enamel $(1.2 \%$ of the experimental units) (Table 3).

Table 3. Mean and standard deviation of shear bond strength and distribution of the failure mode according to treatments.

\begin{tabular}{lccccc}
\hline & & \multicolumn{4}{c}{ Failure mode } \\
\cline { 3 - 6 } Group & Shear BS & $\begin{array}{c}\text { Type 1 } \\
\text { (Adhesive } \\
\text { orthodontic } \\
\text { composite/tube) }\end{array}$ & $\begin{array}{c}\text { Type 2 } \\
\text { (Cohesive in } \\
\text { orthodontic } \\
\text { composite) }\end{array}$ & $\begin{array}{c}\text { Type 3 } \\
\text { (Adhesive } \\
\text { orthodontic } \\
\text { composite/enamel) }\end{array}$ & $\begin{array}{c}\text { Type 4 } \\
\text { (Cohesive in } \\
\text { enamel) }\end{array}$ \\
\hline MZ & $13.64(6.24)$ a & $0(0 \%)$ & $11(55 \%)$ & $5(25 \%)$ & $4(20 \%)$ \\
\hline SB & $12.26(5.38)$ a & $1(1.25 \%)$ & $11(55 \%)$ & $6(30 \%)$ & $2(10 \%)$ \\
\hline OP & $13.15(4.18)$ a & $0(0 \%)$ & $4(20 \%)$ & $13(65 \%)$ & $3(15 \%)$ \\
\hline Control & $10.40(5.70)$ a & $0(0 \%)$ & $6(30 \%)$ & $12(60 \%)$ & $2(10 \%)$ \\
\hline & Total & $1(1.25 \%)$ & $32(40 \%)$ & $36(45 \%)$ & $11(13.75 \%)$ \\
\hline
\end{tabular}

MZ - Metal/Zirconia Primer; SB - Scotchbond Universal; OP - Orthoprimer; N- number of samples per group. Means followed by the same letter indicate no statistical differences. No differences were observed in failure modes among experimental groups, according to Fisher's test $(p=0.1119)$. 


\section{DISCUSSION}

The BS results showed no difference among the orthodontic tubes that were treated with various primers, even those containing acidic phosphate monomers (SB and $\mathrm{MZ}$ ). Dias et al. ${ }^{19}$ observed that the application of an alloy primer (Kuraray) did not increase the BS of the resin cement to zirconia, and the primer did not prevent BS decrease after six months of water storage. The alloy primer contains two functional acidic monomers VBATDT (vinylbenzyl-n-propylamino-triazine-dithiol) and 10-MDP in an acetone-based solution, and it is indicated to cement metal fixed prosthodontics structures.

Similarly, it was previously reported that an Orthoprimer application to polycarbonate-based brackets did not influence the BS results ${ }^{15}$, which is comparable to the findings of our study. The Orthoprimer agent does not contain acidic phosphate monomers except for methacrylate monomers and non-phosphoric hydrophilic monomers (TEGDMA e HEMA) (Table 1). Therefore, it is speculated that this primer is responsible for increasing wettability and improving the resin permeation of the composite in the irregularities of the base of the orthodontic tube. However, it does not chemically bond to the alloy surface as the function monomer does.

Contrary to the present results, Cal Neto et al. ${ }^{20}$ observed that the application of an alloy primer with the acidic monomer 4-META (4-methacryloxyethyl trimellitic anhydride) increased the BS between the composite and the metallic brackets $48 \%$ compared with the control group, whereas in our research, alloy primers were able to increase the BS 17.9 to $31.2 \%$. It should be noticed that these authors used a different primer (4-META) and that this agent could have been more effective in increasing BS compared with the primers selected in this research. The absence of thermal cycles to age the bonded interface, and the fact that the authors used human pre-molars instead of bovine incisors cannot be ruled out.

In a previous study ${ }^{20}$, it was observed that treating the surface of zirconia with alloy primers increased the BS of the zirconia to the metallic bracket. That study used Z-Prime Plus (10-MDP and carboxylic acid) and the Zirconia Liner premium (silane with MDP) ${ }^{20}$. The authors credited the good performance of Z-Prime Plus to the presence of MDP and the ability of the primer to co-polymerize with the resin monomers, as the functional group binds to the metallic oxide of the substrate via the phosphoric group $^{21}$. It is important to notice that MZ, SB, and Z-Prime Plus exhibit different acidic phosphate monomers: the phosphonic acid methacrylate, 1,10-decanediol phosphate methacrylate, and 10-methacryloyloxydecyl dihydrogen phosphate, respectively. Thus, different monomer compositions and application modes may influence BS results ${ }^{22}$. Furthermore, the presence of organophosphate monomers in the universal adhesive SB could promote the instability of the silane component ${ }^{22}$. Therefore, it is possible that the presence of silane hampered the monomer performance and that the adhesive presented similar BS results compared with the other primers.

Thermal cycling (5,000 cycles) was performed for all groups after bonding to age the interface. Previous studies observed that MDP-based primers were effective in preserving the bonding stability to zirconia even after thermal cycling ${ }^{22-24}$. On the other hand, Imai et al. ${ }^{25}$ observed that the BS between composite and alloy surfaces 
decreased after 20,000 thermal cycles. The authors suggested that the lower BS could have been the result of water infiltration in microgaps between the composite and the alloy ${ }^{25}$. As no differences were observed in our study, it is possible that the number of cycles performed could have been insufficient for influencing the BS.

No significant differences were found among the failure modes. In the current study, the shear BS test evaluated multiple interfaces-enamel, orthodontic resin, and the base of the orthodontic tube. Numerically, the most predominant failure was the adhesive type, between the enamel and orthodontic resin (45\%). This may be an indication that the BS at the base of the orthodontic tube where the primer was applied was acceptable. In addition, it should be kept in mind that in shear bond tests, the knife of the apparatus slides down the bordering enamel, stressing the orthodontic resin more than the orthodontic tube. Therefore, as expected, the second more prevalent failure was cohesive failure in the orthodontic composite (40\%). The least prevalent failure was the adhesive type between the orthodontic composite and the base of the orthodontic tube (1.25\%), which might indicate that although the primers did not improve the shear BS, they did not compromise it. In addition, the fact that no differences were found among the BS and failure modes implies that the irregularities at the base of the orthodontic tubes were sufficient for promoting a reasonable BS regardless of the presence of primers.

MZ, OP, and SB exhibited 15\%, 20\% and 10\% respectively, of enamel cohesive defects. Although this type of failure indicates an acceptable performance of the primers applied to the metal, enamel fracture is undesirable when the tubes are removed at the end of orthodontic treatment. Therefore, because no differences were observed among groups, we believe that the decision to apply primers to metallic surfaces should be reexamined, as it could cause enamel fracture during debonding.

Based on the above, the null hypothesis could be accepted, as the application of alloy primers to the base of the orthodontic tubes did not increase the BS to the enamel surface and did not influence the failure modes of the tubes bonded to the enamel surface. Moreover, based on the failure modes and the existence of enamel cohesive failures when primers were applied, we endorse that no need exists to apply alloy primers to orthodontic tubes.

Considering that the application of alloy primers to orthodontic tubes can be dismissed and that debonding occurs due to adhesives (enamel/orthodontic resin) at the orthodontic resin, future research should focus on developing an orthodontic resin that will not fail cohesively and that possesses optimal enamel adhesion that will resist shear forces without compromising enamel integrity when the tube is removed at the end of the orthodontic treatment.

In conclusion, the application of alloy primers did not increase the BS of the orthodontic tube to the enamel. In addition, its application should be better evaluated, as enamel fracture could occur during debonding.

\section{CONFLICT OF INTEREST STATEMENT}

The authors do not have any financial interest in the companies whose materials are included in this article. 


\section{REFERENCES}

1. Murray PG, Millett DT, Cronin M. Bonded molar tubes: a survey of their use by specialist orthodontists. J Orthod. 2012 Jun;39(2):129-35. doi: 10.1179/1465312512Z.00000000016.

2. Al-Anezi SA. The effect of orthodontic bands or tubes upon periodontal status during the initial phase of orthodontic treatment. Saudi Dent J. 2015 Jul;27(3):120-4. doi: 10.1016/j.sdentj.2014.11.010.

3. Pickett KL, Sadowsky PL, Jacobson A, Lacefield W. Orthodontic in vivo bond strength: comparison with in vitro results. Angle Orthod. 2001 Apr;71(2):141-8.

4. Fleming PS, Johal A, Pandis N. Self-etch primers and conventional acid-etch technique for orthodontic bonding: a systematic review and meta-analysis. Am J Orthod Dentofacial Orthop. 2012 Jul;142(1):83-94. doi: 10.1016/j.ajodo.2012.02.023.

5. Brunharo IHVP, Fernandes DJ, Miranda MS, Artese F. Influence of surface treatment on shear bond strength of orthodontic brackets. Dental Press J Orthod. 2013 May-Jun;18(3):54-62.

6. Bakhadher W, Halawany H, Talic N, Abraham N, Jacob V. Factors affecting the shear bond strength of orthodontic brackets - a review of in vitro studies. Acta Medica (Hradec Kralove). 2015;58(2):43-8. doi: 10.14712/18059694.2015.92.

7. Millett, DT, Mandall, NA, Mattick RCR, Hickman J, Glenny AM. Adhesives for bonded molar tubes during fixed brace treatment. Cochrane Database Syst Rev. 2017 Feb 23;2:CD008236. doi: 10.1002/14651858.CD008236.pub3.

8. Pandis N, Christensen L, Eliades T. Long-term clinical failure rate of molar tubes bonded with a selfetching primer. Angle Orthod. 2005 Nov;75(6):1000-2.

9. Ribeiro AA, de Morais AV, Brunetto DP, Ruellas AC, de Araujo MT. Comparison of shear bond strength of orthodontics brackets on composite resin restorations with different surface treatments. Dental Press J Orthod. 2013 Jul-Aug;18(4):98-103.

10. Zhang Y, Sun MJ, Zhang D. Designing functionally graded materials with superior load-bearing properties. Acta Biomater. 2012 Mar;8(3):1101-8. doi: 10.1016/j.actbio.2011.11.033.

11. Thery S, Jaquet D, Mantel M. A Study of Chemical Interactions at the Stainless Steel/Polymer Interface by Infrared Spectroscopy. Part 2: Mechanical properties and study of the interface. J Adhes. 1996:56:15-25

12. Matsumura H, Kamada K, Tanoue N, Atsuta M. Effect of thione primers on bonding of noble metal alloys with an adhesive resin. J Dent. 2000 May;28(4):287-93.

13. Pulido LG, Powers JM. Bond strength of orthodontic direct-bonding cement-plastic bracket systems in vitro. Am J Orthod. 1983 Feb;83(2):124-30.

14. Bulbul, M; Kesim B. The effect of primers on shear bond strength of acrylic resins to different types of metals. J Prosthet Dent. 2010 May;103(5):303-8. doi: 10.1016/S0022-3913(10)60063-7.

15. Souza NF, Vilar RV, Almeida MA, MigueL JA, Cal-Neto JP. Primer on the base of polycarbonate brackets: should we apply it or not? Prog Orthod. 2010;11(1):37-40. doi: 10.1016/j.pio.2010.04.006.

16. Nima G, Ferreira PVC, Paula AB, Consani S, Giannini M. Effect of Metal Primers on Bond Strength of a Composite Resin to Nickel-Chrome Metal Alloy. Braz Dent J. 2017 Jan-Apr;28(2):210-215. doi: 10.1590/0103-6440201701288.

17. Pithon MM, Oliveira MV, Ruellas ACO, Bolognese AM, Romano FL. Shear bond strength of orthodontic brackets to enamel under different surface treatment conditions. J Appl Oral Sci. 2007 Apr;15(2):127-30.

18. Wang WN, Lu TC. Bond strengths with various etching times on young permanent teeth. Am J Orthod Dentofacial Orthop. 1991 Jul;100(1):72-9. 
19. Dias TM, Pacheco RR, De Sá RB, Francescantonio MD, Berger SB, Giannini M. [Evaluation of the effect of metal primers and type of resin cement on the bond strength to zirconia]. Rev Bras Odontol. 2012 Jan-Jun;69(1):15-20. Portuguese.

20. Cal Neto JP, Calasans-Maia JA, de Almeida NV, Rohen H, Freire MA. Effect of a metal primer on the adhesive interface between composite and lingual brackets. J Contemp Dent Pract. 2013 Nov 1;14(6):1106-8.

21. Lee JY, Kim JS, Hwang CJ. Comparison of shear bond strength of orthodontic brackets using various zirconia primers. Korean J Orthod. 2015 Jul;45(4):164-70. doi: 10.4041/kjod.2015.45.4.164.

22. Grifin JD, Suh BI, Chen L, Brown DJ. Surface treatments for zirconia bonding: a clinical perspective. Can J Rest Dent Prosthodont. 2010 Jan.3:23-9.

23. Koizumi H, Nakayama D, Komine F, Blatz MB, Matsumura H. Bonding of resin-based luting cements to zirconia with and without the use of ceramic priming agents. J Adhes Dent. 2012 Aug;14(4):385-92. doi: 10.3290/j.jad.a22711.

24. Nakayama D, Koizumi H, Komine F, Blatz MB, Tanoue N, Matsumura H. Adhesive bonding of zirconia with single liquid acidic primers and a tri-n-butylborane initiated acrylic resin. J Adhes Dent. 2010 Aug;12(4):305-10. doi: 10.3290/j.jad.a17549.

25. Imai H, Koizumi H, Shimoe S, Hirata I, Matsumura H, Nikawa H. Effect of thione primers on adhesive bonding between an indirect composite material and Ag-Pd-Cu-Au alloy. Dent Mater J. 2014;33(5):681-8. 